www.jmscr.igmpublication.org

Impact Factor (SJIF): 6.379

Index Copernicus Value: 71.58

ISSN (e)-2347-176x ISSN (p) 2455-0450

crossrefDOI: https://dx.doi.org/10.18535/jmscr/v6i7.134

Journal Of Medical Science And Clinical Research

IGM Publication

An official Publication of IGM Publication

\title{
Study of Correlation between Visual Analogue Scale and Peak Expiratory Flow Rate Measurement to Assess Severity of Bronchial Asthma
}

\author{
Authors \\ Toke $\mathrm{SK}^{1}$, Singh $\mathbf{R B}^{2}$ \\ ${ }^{1}$ Senior Resident, Dept of Pulmonary Medicine, MIMER Medical College,Talegaon D, Pune. \\ ${ }^{2}$ Senior Consultant, Dept of Respiratory Medicine, Apollo Hospitals Chennai \\ Corresponding Author \\ Toke SK
}

Senior Resident, Dept of Pulmonary Medicine, MIMER Medical College, Talegaon D, Pune, India Mob no : 9503553685, Email: sahebraotoke@gmail.com

\begin{abstract}
Bronchial asthma is a chronic inflammatory disorder of the airways. Asthma patient experiences symptoms like cough, dyspnea, wheeze, chest tightness. Dyspnea is often used as a marker of severity of asthma. The severity of bronchial asthma is best judged by spirometry using parameters like FEVI and PEFR. In rural areas spirometry assessment is difficult because of limited access to medical facilities, lack of or interrupted supply of electricity, unavailability of trained technician and poverty. Visual analogue scale (VAS) is a tool used to help a person to rate the intensity of certain feelings \& sensations. Severity of dyspnea can be assessed by visual analogue scale. After explaining study and taking written informed consent, 100 bronchial asthma patients having age more than 18 years were selected randomly. We divided the patients in three groups according to FEVlas mild, moderate and severe.VAS chart was handed over to patients. Each patient was asked to mark in the chart according to his/her dyspnea. PEFR was measured immediately after recording of VAS using mini peak flow meter. At each instance three recordings were taken with thirty seconds interval \& best reading was used for analysis.

All mild, moderate and severe asthma groups showed strongly significant correlation between visual analogue scale and PEFR (Pearson $r=-0.8472$ ). There was strong correlation between visual analogue scale and FEVI (Pearson $r=-0.7157$ ) in asthma patients. This study also showed strong correlation between PEFR and FEVI in moderate and severe groups of asthma patients. We conclude that visual analogue scale can be a used to assess severity of bronchial asthma except in poor perceivers of symptoms. Keywords: Visual analogue scale (VAS), PEFR.
\end{abstract}

\section{Introduction}

Bronchial asthma is a chronic inflammatory airway disorder. Global prevalence of bronchial asthma ranges from $1 \%$ to $18 \%$ of the population in different countries. ${ }^{1,2}$ In India prevalence of bronchial asthma ranges from $1.3 \%$ to $3.9 \%$ in adults \& $1.9 \%$ to $12.8 \%$ in children. Bronchial asthma is slightly higher in rural areas than urban. $^{2}$

The severity of bronchial asthma is best assessed by spirometry and it is the preferred investigation. But in rural areas it is difficult to perform spirometry repeatedly for assessing the severity of asthma because of poverty, limited access to 
medical facilities, lack or interrupted supply of electricity, unavailability of trained technician.

Bronchial asthma severity can be assessed by other methods like IUATLD, ISAAC questionnaire, physical examination but these are not accurate. ${ }^{2}$ Always there is some mismatch between real life breathlessness \& lung functions. Peak expiratory flow rate is one of the most widely used objective measures of bronchial obstruction. But PEFR is not free from errors because it is effort dependent. This measurement does not take into account the subjective wellbeing of the patient.

Asthmatic patient experiences symptoms like dyspnea, cough, wheeze, chest tightness. ${ }^{3,4}$ Dyspnea is often used as a marker of asthma severity, although a wide variation in dyspnea perception is associated with bronchoconstriction in asthmatic patients. ${ }^{5}$ Visual analogue scale is a tool used to help a person to rate the intensity of certain feelings \& sensations. ${ }^{6}$ Dyspnea can be assessed by visual analogue scale. So this study was aimed to assess severity of bronchial asthma by rating dyspnea on visual analogue scale. We did correlation between visual analogue scale (VAS) with peak expiratory flow rate (PEFR) in mild, moderate and severe bronchial asthma groups.

\section{Material \& Methods ${ }^{7}$}

The present study was undertaken at the Department of Respiratory Medicine Apollo Hospitals, Chennai, India after institutional ethics committee approval. The study was done during period extending from March 2009 to February 2011.

The diagnosis of bronchial asthma was established on the basis of history, physical examination and reversible airflow obstruction on spirometer. $(>12 \%$ increase in FEV1 after inhaled bronchodilator).

Bronchial asthmatic patients visiting our outpatient department of Respiratory Medicine were screened according to inclusion exclusion criteria. Detailed clinical examination \& past history was taken.

After explaining study and taking written informed consent, 100 bronchial asthma patients having age more than 18 years were selected randomly. All smokers, patients with pulmonary tuberculosis, cardiac diseases and interstitial lung diseases were excluded from the study. In our study, we used visual analogue scale of ' $10^{\prime} \mathrm{cm}$ in length, on which scaling is done from ' 0 ' $\mathrm{cm}$ to ' 10 ' $\mathrm{cm}$. ' 0 ' $\mathrm{cm}$ means no breathlessness \& ' 10 ' $\mathrm{cm}$ means maximum breathlessness. Visual analogue scale chart was handed over to patients. Each patient was asked to mark in the chart according to his/her dyspnea. PEFR was measured immediately after recording of VAS using mini peak flow meter. At each instance three recordings were taken with thirty seconds interval $\&$ best reading was used for analysis. The patients were divided into mild, moderate and severe groups according to GINA guidelines ${ }^{8}$

\section{Statistics}

Statistical analysis was done using the statistical software SPSS version 10.0. Correlation of VAS with both PEFR and FEV1 was done by using Pearson's correlation coefficient. Comparison of VAS, PEFR and FEV1 among mild, moderate and severe groups was done by ANOVA. P-value $\leq$ 0.05 was considered significant.

\section{Results}

Table 1: Comparison between the VAS, PEFR and FEV1 among three groups is done by ANOVA.

\begin{tabular}{|l|c|c|c|c|}
\hline Subjects & Age & FEV1 & PEFR & VAS \\
\hline Severe $(\mathrm{n}=62)$ & $47.89 \pm 13.73$ & $45.03 \pm 9.302$ & $41.87 \pm 12.84$ & $4.984 \pm 1.996$ \\
\hline Moderate(n=33) & $42.39 \pm 14.12$ & $68.49 \pm 5.897$ & $56.27 \pm 15.56$ & $3.242 \pm 1.480$ \\
\hline Mild $(\mathrm{n}=5)$ & $25.80 \pm 5.357$ & $86.38 \pm 2.381$ & $79.80 \pm 8.786$ & $0.8000 \pm 0.8367$ \\
\hline p-value & $0.1363 \mathrm{~ns}$ & $<0.0001 * * *$ & $<0.0001 * * *$ & $<0.0001 * * *$ \\
\hline
\end{tabular}


Table 2: Correlation coefficients of VAS score with PEFR and FEV1

\begin{tabular}{|l|c|c|c|}
\hline Asthmatic groups & VAS vs PEFR & VAS vs FEV1 & PEFR vs FEV1 \\
\hline Severe asthma $(\mathrm{n}=62)$ & $-0.8309^{* * *}$ & $0.1506 \mathrm{~ns}$ & $0.5459^{* * *}$ \\
\hline Moderate asthma $(\mathrm{n}=33)$ & $-0.7344^{* * * *}$ & $-0.4700^{* *}$ & $0.4123^{*}$ \\
\hline Mild asthma $(\mathrm{n}=5)$ & $-0.8910^{*}$ & -0.1280 & $0.5077 \mathrm{~ns}$ \\
\hline Overall $(\mathrm{n}=100)$ & $-0.8472^{* * *}$ & $-0.7157^{*}$ & $0.6933^{* * *}$ \\
\hline P value $<0.05^{*}$ & \\
\hline
\end{tabular}

Table 3: Correlation of VAS and PEFR in asthmatic patients

\begin{tabular}{|l|c|}
\hline Number of XY Pairs & 100 \\
\hline Pearson $\mathrm{r}$ & -0.8472 \\
\hline 95\% confidence interval & -0.8947 to -0.7807 \\
\hline P value (two-tailed) & $<0.0001$ \\
\hline P value summary & $* * *$ \\
\hline Is the correlation significant? (alpha $=0.05$ ) & Yes \\
\hline R squared & 0.7178 \\
\hline
\end{tabular}

Graph 1: correlation of VAS and PEFR in asthmatic patients

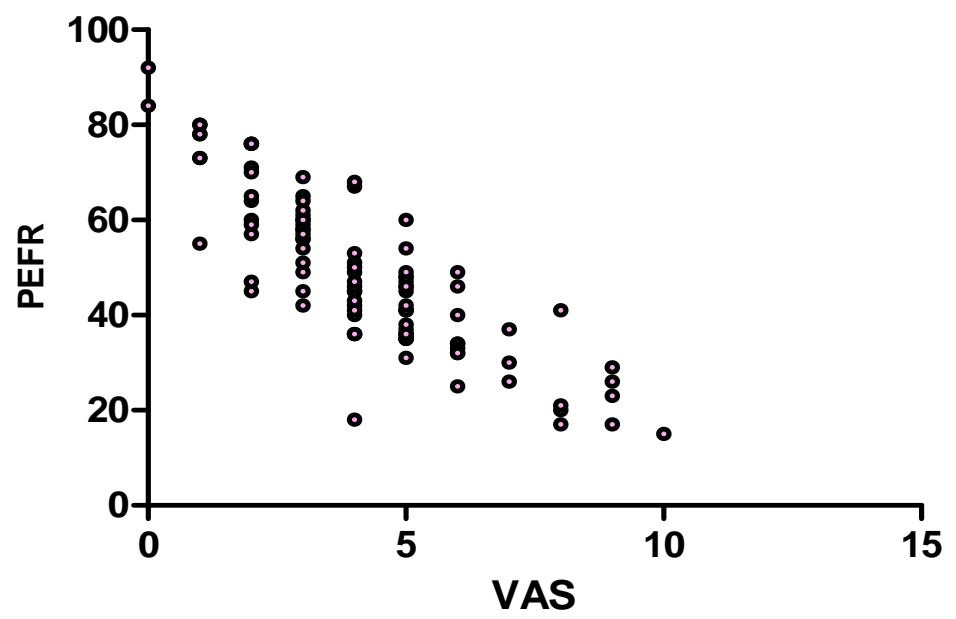

\section{Discussion}

All mild, moderate and severe asthma groups showed good correlation between visual analogue scale and PEFR (Pearson $r=-0.8472$ ). There was strong correlation between visual analogue scale and FEV1 in mild and moderate asthma patients. This study also showed strong correlation between PEFR and FEV1 in moderate and severe groups of asthma patients.

Gupta D et al also showed strong correlation between spirometry parameters \& visual analogue scale, without any effect of educational status of patient. ${ }^{9}$ Guleria $\mathrm{R}$ et al also showed that there is correlation between lung function tests with dyspnea scale and VAS in patients with COPD ${ }^{10}$
From our results we conclude that visual analogue scale can be a used to assess severity of dyspnea in bronchial asthmatic patients except in poor perceivers of symptoms.

\section{Application of the study}

Result of this present study shows visual analogue scale can help to clinically assess the severity of bronchial asthma. In rural setting, visual analogue scale can be useful for assessing the severity of asthma as it does not require electricity, trained manpower and extra cost. Bronchial asthma is a chronic condition and it needs continuous medical care. Moderate to severe asthma patients need to take long-term anti-inflammatory drugs daily. So not only for assessing the severity, visual analogue scale can be used to evaluate and 
monitor the effectiveness of treatment of asthma. The procedure is very simple, reproducible and can be completed in very less time. Nurses and paramedical staff can also do the procedure and grade the severity and can monitor the effectiveness of treatment of patient's asthma.

There was no any conflict of interest.

\section{References}

1. Maroli M, Fabian D, Holt S, Beasley R. The Global burden of Bronchial Asthma Executive summary of the GINA dissemination committee report. Allergy. 2004; 59(5): 469-78.

2. SutapaAgrawal. South Asia Network for chronic Disease. New Delhi, India: 2010. Available from: http//www.sancd.org/uploads/pdf/Asthma_ factsheet.pdf ..

3. Lai CK, De Guria TS, Kim YY, Kuo SH, Mukhopadhyay A, et al. Bronchial Asthma Control in Asia-Pacific region; the Bronchial Asthma Insights and Reality in Asia - Pacific study. J Allergy ClinImmunol. 2003; 111 (2): 263-8.

4. Boulet LP. Asymptomatic airway hyper responsiveness: a curiosity or an opportunity to prevent Bronchial Asthma. Am J Respir Crit Care Med. 2003; 167(3): 371-8.

5. Killian KJ, Watson R, Otis J, St Amand TA, O'Byrne PM. Symtom perception during acute bronchoconstriction. Am J Respir Crit Med. 2000; 162 (2Pt 1): 490-6.

6. Haefeli M, Elfering A. Pain assessment European Spine Journal. 2006;15(Suppl 1):S17S24.doi:10.1007/s00586-005-1044-x.

7. Taube C, Lehnigk B, Paasch K, Kirsten DK, Jörres RA, Magnussen H. Factor Analysis of Changes in Dyspnea and Lung Function Parameters after Bronchodilation in Chronic Obstructive Pulmonary
Disease.Am J Respir Crit Care Med. 2000 Jul;162(1):216-20

8. Koshak EA. Classification of asthma according to revised 2006 GINA: Evolution from severity to control. Annals of Thoracic Medicine. 2007;2(2):45-46. doi:10.4103/1817-1737.32228.

9. Gupta D. Aggarwal A.et al . Assessing severity of asthma: Spirometric correlates with Visual Analogue Scale (VAS).Indian Journal of Chest dis allied Sci. 2000;42:95-100.

10. Guleria R, Behera D, Jindal SK. Correlation of lung function tests with dyspnea scale:12-minute walking test and visual analogue scale in patients with COPD. Indian $\mathbf{J}$ Chest Dis Allied Sci. 1989;31: 241-245. 